\title{
The Primates 2020 Social Impact Award
}

\section{Tetsuro Matsuzawa ${ }^{1}$}

Published online: 6 January 2021

(c) Japan Monkey Centre 2021

It is my pleasure to announce the winners of the Primates 2020 Social Impact Award. These high social impact papers have been selected by me, Editor-in-Chief of Primates, and the two Vice Editors-in-Chief, James R. Anderson and Satoshi Hirata, based on data sources such as the Altmetric score (calculated from the number of mentions in the media and on social-networking sites) and on the number of fulltext downloads.

The Primates 2020 Social Impact Award goes to the following three papers (in alphabetical order of the first author):

Shifra Z. Goldenberg, George Wittemyer (2020) Elephant behavior toward the dead: a review and insights from field observations. (Primates 61:119-128, 2020).

Zoë Goldsborough, Edwin J. C. van Leeuwen, Kayla W. T. Kolff, Frans B. M. de Waal, Christine E. Webb (2020) Do chimpanzees (Pan troglodytes) console a bereaved mother? (Primates 61:93-102, 2020).
Louise R. Peckre, Charlotte Defolie, Peter M. Kappeler, Claudia Fichtel (2018). Potential self-medication using millipede secretions in red-fronted lemurs: combining anointment and ingestion for a joint action against gastrointestinal parasites? (Primates 59:483-494, 2018).

These three papers received a great deal of media attention, were frequently mentioned on social networking sites, and were downloaded numerous times. The work of their authors thus contributed greatly to enhancing the reputation of our journal.

Please join us in congratulating them!

Tetsuro Matsuzawa, Editor-in-Chief, Primates

Tetsuro Matsuzawa

matsuzawa.tetsuro.8w@kyoto-u.ac.jp

1 Kyoto University, Kyoto, Japan 


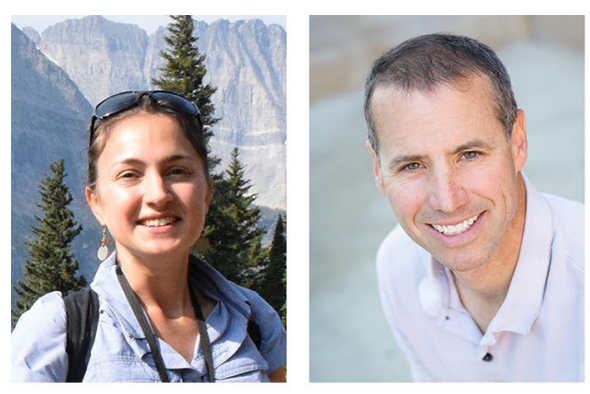

From the left: Shifra Z. Goldenberg, George Wittemyer
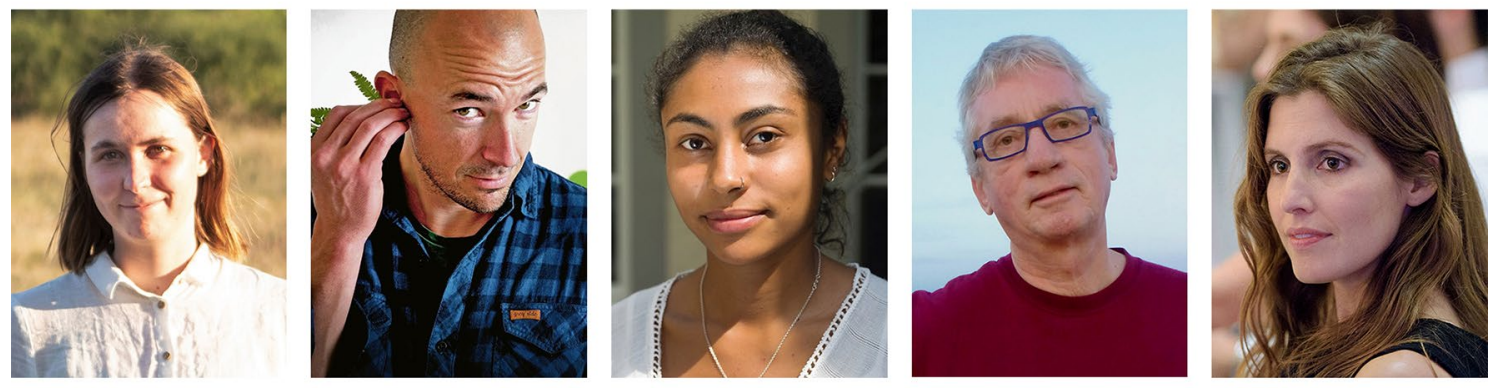

From the left: Zoë Goldsborough, Edwin J. C. van Leeuwen, Kayla W. T. Kolff, Frans B. M. de Waal, Christine E. Webb
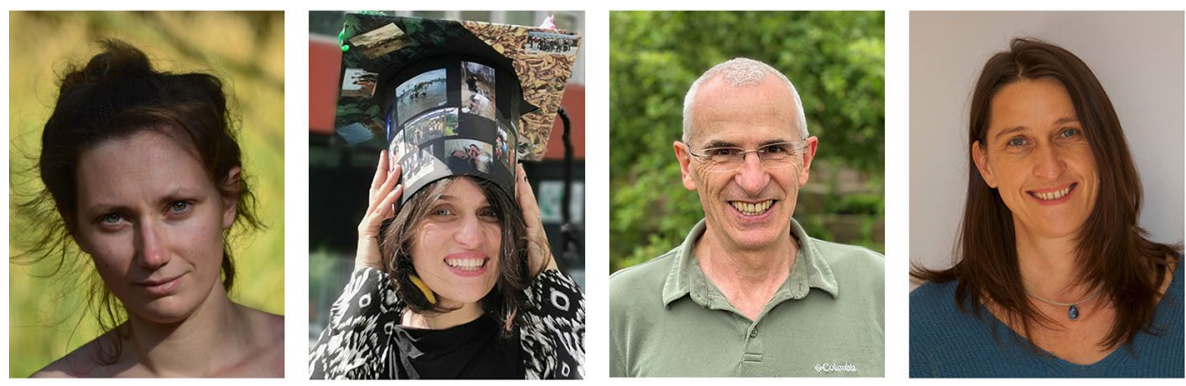

From the left: Louise R. Peckre, Charlotte Defolie, Peter M. Kappeler, Claudia Fichtel

\section{References}

Goldenberg SZ, Wittemyer G (2020) Elephant behavior toward the dead: a review and insights from field observations. Primates 61:119-128. https://doi.org/10.1007/s10329-019-00766-5

Goldsborough Z, van Leeuwen EJC, Kolff KWT, de Waal FBM, Webb CE (2020) Do chimpanzees (Pan troglodytes) console a bereaved mother? Primates 61:93-102. https://doi.org/10.1007/s10329-01900752-x

Peckre LR, Defolie C, Kappeler PM, Fichtel C (2018) Potential selfmedication using millipede secretions in red-fronted lemurs: combining anointment and ingestion for a joint action against gastrointestinal parasites? Primates 59:483-494. https://doi. org/10.1007/s10329-018-0674-7

Publisher's Note Springer Nature remains neutral with regard to jurisdictional claims in published maps and institutional affiliations. 